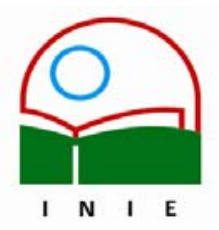

Universidad de Costa Rica

Facultad de Educación

Instituto de Investigación en Educación

ACTUALIDADES INVESTIGATIVAS EN EDUCACION

\title{
EL SENTIDO SOCIAL DE LA IDEA DE UN BUEN MAESTRO
}

\section{Alejandrina Mata Segreda ${ }^{1}$}

Resumen: Este artículo describe el proceso de investigación desarrollado para la elaboración del sentido social de la idea de un buen maestro, por parte de un grupo de niñas y niños, madres y padres de familia, y profesores y profesoras de las carreras de Educación de las universidades estatales costarricenses. Con la aplicación de un enfoque cualitativo en el que se utilizó la estrategia de análisis de contenido mediante la técnica de análisis de contingencias, se le dio respuesta al siguiente problema de investigación: ¿Cuál es la correspondencia teórica entre el sentido social de la idea del "buen maestro"y los enfoques normativo y descriptivo para la formación inicial de educadores? Desde el punto de vista del enfoque normativo de formación de educadores, las características que mayormente se destacan son: tiene personalidad de maestro, tiene destrezas de maestro y practica conductas de maestro. En concordancia con el enfoque descriptivo de formación de educadores, las características que se destacan son las siguientes: desarrolla y aplica estrategias de pensamiento, desarrolla y aplica estrategias de percepción u observación, desarrolla su capacidad para la toma de decisiones, sabe considerar el contexto y puede individualizar su tarea. Se concluye que persisten percepciones en el grupo de participantes que elaboran un imaginario del maestro ideal tanto desde la perspectiva normativa como la descriptiva. En el caso de las percepciones basadas en el enfoque normativo, éstas ocasionan un sentimiento de inadecuación para la tarea docente por parte de estos profesionales, con sus consecuencias negativas.

Palabras clave: BUEN MAESTRO/ FORMACIÓN DOCENTE/ INVESTIGACIÓN CUALITATIVA/ ANÁLISIS DE CONTENIDO/ GRUPOS DE DISCUSIÓN/

\begin{abstract}
This article describes the research process applied to identify the social sense of the idea of a good teacher, as viewed by a group of children, parents and university professors from state universities of Costa Rica. The research problem was stated as "What is the theoretical relation between the idea of a good teacher with the normative and descriptive approaches for teacher education?", and it was answered using a qualitative approach with focus groups and content analysis. From the normative approach of teacher education, the most important characteristics found were: they have "teacher personality" and "teacher skills", and they practice "teacher behaviors". From the descriptive approach, the most important characteristics found were: they develop and apply thought and perception or observation skills, they develop their decision making capacities, they consider the context and can individualize their tasks. The conclusion is that there are perceptions among the participants in the research, related with ideas of a good teacher from both approaches. Those ideas related to the normative approach make teachers feel unsuited for the teaching job, with its negative consequences.
\end{abstract}

Key words: GOOD TEACHER/ TEACHER EDUCATION/ QUALITATIVE RESEARCH/ CONTENT ANALYSIS/ FOCUS GROUPS/

\section{DEFINICIÓN DEL PROBLEMA}

En el contexto demarcado por el sistema educativo formal, la tarea educativa es producto de la acción e interacción de múltiples variables. Desde el punto de vista del estudiante se destacan sus facultades para el aprendizaje, la calidad del ambiente sociocultural del que proviene y los insumos o recursos materiales que su familia pone a su disposición. La

\footnotetext{
${ }^{1}$ Magister Scientiae en Educación de Adultos de la Universidad de Costa Rica. Diploma Estudios Avanzados del Programa de Doctorado en Educación Comparada de la Universidad Nacional de Educación a Distancia, España. Actualmente es profesora de la Escuela de Orientación y Educación Especial de la Universidad de Costa Rica. Integrante de la Comisión Interuniversitaria de Educación Ambiental (CONARE). Correo electrónico: amatas@cariari.ucr.ac.cr
}

Artículo recibido: 16 de setiembre, 2003

Aprobado: 29 de noviembre, 2003 
organización misma del sistema, incluyendo el plan de estudios y el currículo en general, es otro de los elementos por considerar, al igual que la mediación e intención educativa bajo la responsabilidad del profesor como elemento desencadenante del cumplimiento preciso de los objetivos del sistema educativo. Cada uno de estos elementos requiere de la atención de los responsables de las políticas y la administración del sistema mediante decisiones fundadas sobre todo en la investigación y en la evaluación de los sistemas educativos. El interés del presente trabajo se centra en la figura del educador. El perfil de este profesional, y la evaluación de su quehacer constituyen elementos básicos para realimentar las políticas educativas y los proyectos pedagógicos en concreto. En cuanto a la formación inicial y continua del profesorado, si bien es cierto existe investigación de carácter general que en la actualidad ofrece fundamento para construir el perfil de este profesional en concordancia con las tendencias educativas y los acontecimientos mundiales, no es menos cierto que también deben promoverse estudios que respondan a los intereses de cada comunidad específica atendiendo su contexto sociocultural. Se ha hecho énfasis en que es necesario, entre otras cosas, proceder a concretar mejor las funciones del profesor o las competencias profesionales que se requieren para atender las necesidades educativas de los escolares y de la misma comunidad (Imbernón, 1994), y para cumplir con las expectativas de los beneficiarios de los servicios educativos y de la actuación docente.

Con el propósito de ofrecer un acercamiento sobre el sentido social que se le da a la idea de un buen maestro, que permita el enriquecimiento de políticas educativas en el campo de la formación inicial y continua de educadores, se ha planteado el siguiente problema de investigación:

¿Cuál es la correspondencia teórica entre el sentido social de la idea del "buen maestro"y los enfoques normativo y descriptivo para la formación inicial de educadores?

Toda cultura elabora simplificaciones generalizadoras de la realidad, las que constituyen los estereotipos sociales. Estos ejercen presiones que mantienen no sólo las concepciones sociales, sino también que marcan un camino hacia el cual se orientan las políticas públicas y las acciones concretas de quienes están a cargo de ellas. Este es el caso del estereotipo social del "buen maestro", cuya presión se hace presente no sólo en las concepciones sociales sino también en muchas de las instituciones dedicadas a la formación de educadores (Esteve, 1996). 
La ideología en su sentido amplio, como conjunto de producciones significantes que operan como reguladores de lo social (Canales y Peinado, 1994), no necesariamente debe ser considerada como el elemento exclusivo que determine las actuaciones sociales públicas conscientes. Se ha visto cómo a lo largo de la historia, la humanidad se ha enfrentado a acontecimientos basados en ciertas concepciones ideológicas que han resultado desastrosos para su supervivencia, por lo que no se trata de aceptar de manera incuestionable, el predominio de estereotipos que a todas vistas afectan negativamente el desarrollo armónico de la sociedad. Por esta razón, la clarificación del sentido social de la idea de un "buen maestro" tendría como propósito la toma de su conciencia, la definición de expectativas sociales acerca de este profesional, y la propuesta posterior de acciones para la reconstrucción de este sentido en las actuaciones sistemáticas, como sería la formación de educadores, y la propuesta de elementos o indicadores propios para su evaluación.

El enfoque teórico que orientó la construcción del objeto en estudio es el planteado por Esteve (1996) acerca de los enfoques normativos y los enfoques descriptivos en la formación inicial de los educadores. De acuerdo con este autor, se entiende por enfoques normativos aquellos que se orientan por un modelo de profesor eficaz o bueno que recoge el conjunto de cualidades atribuidas al buen profesor en una sociedad y en un momento histórico determinados. Por el contrario, los enfoques descriptivos para la formación de educadores consideran que el éxito en la docencia depende de una actuación correcta del profesor que responda al conjunto de condicionantes que influyen en la interacción profesor alumno, lo que plantea diferentes modelos de eficacia para diversas situaciones educativas. La investigación desarrollada alrededor de este último enfoque ha demostrado que incide de manera más positiva en la resolución de los problemas a los que se enfrenta el educador.

Para una mejor comprensión del problema de investigación es preciso definir dos conceptos básicos. En primera instancia se entiende sentido social como la construcción conjunta, mediante la palabra, de una idea entre miembros de un grupo, que muestra un campo semántico que define cuáles elementos son incluidos como pertinentes y sus relaciones recíprocas, y qué elementos excluye y qué relaciones no acepta. De este modo, lo incluido y lo excluido se muestran y explican recíprocamente mediante el análisis que realizan los observadores participantes del grupo, y va más allá de la conciencia individual y de la mera aceptación de los postulados explícitos (Canales y Peinado, 1994). Esto se da gracias a que 
en los agrupamientos sociales, el mecanismo fundamental de interacción es el lenguaje en todas sus formas, y de manera especial la palabra. Es un mediador simbólico al igual que toda forma de lenguaje, desde el oral al corporal, desde la forma gráfica al movimiento en el espacio, desde la palabra a la marca, que si bien ejerce su acción en espacios heterogéneos, tal vez distantes, pueden ser integrados o incorporados para conformar un contexto del que brota el significado de acciones o sentimientos expuestos a la observación o interpretación (García Carrasco y García del Dujo, 1996). Al hacerse referencia al concepto sentido social, lo que se busca es que, a partir de la expresión de ideas o imágenes individuales, se elabore una imagen colectiva, consensuada, y con significados comunes para los miembros de un grupo social determinado, es decir, una construcción común mediante la palabra, que refleje una parte de la realidad social.

Para definir el concepto de idea de buen maestro es necesario considerar que la formación de imágenes proporciona al individuo análogos cognitivos, modelos representativos de los objetos de conocimiento, apoyan al pensamiento y también lo condicionan y limitan. Las funciones imaginativas (ideas) que suscita una palabra configuran en parte el campo de significado de esa palabra (García Carrasco y García del Dujo, 1996). La imagen que individualmente se elabora sobre un maestro adecuado o inadecuado, según sea la experiencia del hablante, constituye el elemento provocador, mediante su producción verbal, de la construcción de un objeto de estudio necesario para la definición de criterios relacionados con políticas educativas, lineamientos curriculares para la formación de este profesional, consideraciones acerca del papel que juega en el desarrollo social e individual, y fundamento para el pilotaje del sistema educativo. Dentro de una perspectiva humanista del pilotaje de los sistemas educativos (de Landsheere, 1999), la experiencia tal y como es vivida por cada persona y el sentido que ésta le da, constituyen insumos necesarios para la gestión de los sistemas educativos. El propósito del presente trabajo es definir de manera sistemática el modo de ver el desempeño apropiado de un educador, es decir, la formación imaginativa suscitada por las palabras maestro bueno.

\section{OBJETIVOS DE LA INVESTIGACIÓN}

1. Elaborar una reproducción del sentido social que se le da a la idea de buen maestro en un grupo de estudiantes de primaria, padres de familia y formadores de educadores.

2. Identificar la correspondencia existente entre el sentido social de la idea de buen maestro y los enfoques normativo y descriptivo para la formación de educadores. 


\section{JUSTIFICACIÓN}

a. De acuerdo con Marchesi y Martín (1998), los retos principales a los que se enfrenta la educación en este momento se refieren, entre otros, a la búsqueda de la calidad educativa. Como parte de este tema se ubica la preocupación por la función docente pues se ha considerado factor central del progreso y del cambio en educación. Este aspecto ha sido abundantemente discutido en diversos foros nacionales e internacionales, como por ejemplo, el foro Calidad de la Educación desarrollado por la ANDE en Costa Rica en 1999, la Reunión de consulta técnica sobre formación y condición docente organizada por la OEI en Chile en 1998, el informe de la UNICEF sobre educación de 1999, el informe sobre el estado de la Educación en América Latina y el Caribe del PNUD de 1999, el informe de la IHEAL sobre los desafíos de la educación en América Latina del año 2000, entre otros. Ahora bien, la forma en que se manifiesta y se busca resolver tal preocupación no necesariamente responde a una visión unificada del problema, sino que responde a condiciones contextuales diferentes, al igual que a distintas visiones teóricas. Las orientaciones teóricas y políticas juegan un papel determinante en la definición de criterios de evaluación de los sistemas educativos y del papel del educador, lo que resulta indispensable caracterizar de acuerdo con determinado contexto social para permitir la propuesta futura de indicadores de calidad para la evaluación de los sistemas educativos. Identificar el sentido social en una porción del ámbito costarricense, de lo que es un buen maestro, significa contar con la información sobre las expectativas sociales y culturales sobre este tema para realimentar los procesos de formación inicial e incidir en la reconstrucción de los significantes que operan como reguladores de tales expectativas.

b. De acuerdo con Arroyo (2001), antes de ser medida y evaluada la calidad, deber ser definida de manera particular. Según este autor, los organismos reguladores de la educación costarricense como el Ministerio de Educación, el Consejo Superior de Educación, diversas entidades de la UNESCO y la OREALC, poseen una visión estandarizada y normativa del proceso educativo y de la forma de evaluarlo al aplicar consideraciones ajenas a los componentes del sistema educativo. Uno de estos componentes lo constituyen los educadores a quienes podría estárseles demandando determinado ejercicio profesional, determinada forma de impartir la docencia, determinadas conductas y actitudes que no necesariamente responden al ideal educativo de una sociedad, pero peor aún, que no corresponden a las exigencias de la tarea educativa. Reproducir el sentido social de la 
concepción de un buen maestro contribuiría a la construcción de indicadores de calidad de la docencia, y en correspondencia con un marco teórico determinado, se buscaría preparar a profesorado para enfrentar más exitosamente las principales tensiones existentes en su desempeño profesional.

\section{REFERENTES TEÓRICOS}

Para lograr explicar la tendencia ideológica referente al sentido social de la idea del buen maestro, era necesario escoger un marco teórico que orientara la identificación de las variables o elementos predominantes o excluidos de esta construcción social, de otra manera el estudio hubiera quedado como una simple recolección de datos organizados de acuerdo con el predominio de temas, y sin poder sacar provecho de ellos para ser aplicados a la resolución de problemas relacionados con el campo educativo. Los enfoques normativos y descriptivos para la formación de educadores resultan pertinentes para realizar una tarea que va más allá de la simple recolección y organización de la información. Mediante su aplicación en el análisis de los resultados de la presente investigación, es posible hacer objetivo y operativo este sentido social, de manera útil no sólo al campo de la formación de educadores, sino también a la formación continua de estos profesionales, a la elaboración de políticas curriculares, al rescate de la imagen del educador, y a la evaluación de su quehacer docente. A continuación se hará una descripción de los elementos sustantivos aplicables a este estudio.

Diversos estudios sobre la evolución histórica de los modelos o enfoques aplicados a la formación inicial de educadores (Imbernón, 1994), constatan el predominio en el tiempo de tendencias basadas en normas que idealmente deben adoptarse como componentes de la personalidad o de la conducta del profesor. Ejemplo de lo anterior se encuentra en el paradigma presagio-producto que pone énfasis en la competencia docente concentrándose en la personalidad del profesor. Se presagia el éxito en la docencia si el profesor es reflejo de una personalidad ya preconcebida de acuerdo con caracterizaciones tradicionales que responden a concepciones sociales y culturales de la misión del maestro y la escuela. De igual manera se ha logrado caracterizar el paradigma proceso-producto que más bien centra la efectividad del maestro en las destrezas concretas y las conductas específicas que se relacionan positivamente con el rendimiento de los escolares. A manera de recetas, esta perspectiva sugiere que el éxito en la docencia es independiente de las condiciones existentes en la escuela y en la relación profesor estudiante, para referirlo exclusivamente al 
cumplimiento de pasos y procedimientos referentes exclusivamente a la técnica, estrategia o método que se esté aplicando. Supone que el cumplimiento estricto de acciones que han probado, desde el punto de vista metodológico, ser eficientes y efectivas, es suficiente para atender la diversidad de necesidades de los educandos.

Sobre la base de estos modelos constituidos en norma, se trasmite al profesor en formación lo que debe hacer, pensar y evitar para adecuar su actuación educativa al modelo propuesto. Se supone que la conducta del profesor es un reflejo de su personalidad y cuando éste se enfrenta a fracasos en el ejercicio de su profesión, descubre que su personalidad tiene bastantes limitaciones que no encajan con el modelo de profesor ideal. Así desarrolla un sentimiento total de inadecuación para la tarea, que conlleva la paralización (Esteve, 1996).

El sentimiento de inadecuación para la tarea docente no sólo es producto del modelo aplicado en el proceso de formación inicial de los educadores, sino que más recientemente se ve incrementado debido a las transformaciones como consecuencia del cambio social, y que exigen a estos profesionales una adecuación de sus tareas. De acuerdo con Esteve, Franco y Vera (1995), en los últimos 20 años, en el ámbito europeo, diversos cambios sociales, políticos y económicos han configurado un panorama muy distinto para el profesorado. Entre los factores que han influido se destaca un auténtico proceso histórico de aumento a las exigencias que se hacen al profesor, pidiéndole asumir cada vez mayor número de responsabilidades, mientras que otros agentes de socialización se han inhibido en sus responsabilidades educativas. Todo esto en medio de una trasformación vertiginosa de la influencia de los medios de comunicación como agentes socializadores y un descenso en la valoración social del profesor.

Una situación similar, en términos de impacto del cambio, enfrentan los educadores costarricenses. De acuerdo con el Octavo Informe del Estado de la Nación en Desarrollo Humano Sostenible (2002), las condiciones económicas y sociales del país se polarizan cada vez más y a mayor velocidad. La inversión en educación se ha incrementado pero en términos nominales, las expectativas acerca de la democracia costarricense incluyen con mayor amplitud el acceso a la educación de buena calidad, se deteriora el papel de la familia en medio de influencias externas de gran empuje, entre otras condiciones. De este informe se pueden interpretar los elementos de cambio a los que se enfrentan los profesores, concretándose algunos de ellos: 
a. Escasez de recursos económicos para la inversión en infraestructura escolar, materiales educativos y equipo tecnológico para la docencia, no obstante estos insumos cada día son más valorados por la sociedad, y más necesarios para que la escuela pueda competir exitosamente con los medios de comunicación de masas.

b. Incremento de las tasas de embarazo adolescente, lo que exige del profesorado una atención renovada a la educación para la sexualidad. La idea de sexo como pecado, si bien es cierto aún sigue siendo difundida por la Iglesia, no ha sido factor suficiente para que los jóvenes vivan una sexualidad más sana, y en cambio se han incrementado los índices de embarazo. Para los educadores es imprescindible asumir posiciones completamente diferentes con respecto a la formación integral de sus estudiantes.

c. Incremento en el número de estudiantes con discapacidad que se integran al sistema educativo regular, lo que exige al profesorado atender condiciones muy diversas en el aula. Las políticas nacionales están orientadas más bien hacia la educación inclusiva, exigiendo a los profesores realizar adecuaciones curriculares y de acceso para garantizar la educación de niños y jóvenes con discapacidad y otras necesidades educativas particulares, en condiciones de igualdad.

d. Aumento en un $500 \%$ en los últimos 20 años de los inmigrantes nicaragüenses, que matriculan a sus hijos en las escuelas regulares. Aparte de que el país no puede controlar efectivamente el ingreso de inmigrantes indocumentados, la legislación nacional, los acuerdos sobre la niñez y la adolescencia, y los compromisos internacionales, han exigido al sistema educativo atender a estos inmigrantes en igualdad de condiciones que los costarricenses, enfrentando el maestro condiciones culturales diversas que dificultan o exigen una transformación de su labor docente.

e. Los niveles de deserción escolar permanecen constantes, a pesar de los esfuerzos estatales, situación que se atribuye a la falta de pertinencia de la educación que se ofrece en las instituciones educativas. Al suponerse que la escuela debe competir con el ambiente moderno en que se desenvuelven los jóvenes para lograr atraerlos y mantenerlos en el sistema educativo, se crea en el profesor un sentimiento de inadecuación para la tarea docente. Este sentimiento en general debe enfrentarse solo puesto que en sí, el sistema educativo y la administración de éste, no ofrecen soluciones que resuelvan la situación general. 
Ante estos retos ocasionados por la transformación social, Esteve, Franco y Vera (1995) proponen tres grandes líneas de actuación para impactar los procesos de formación inicial de educadores, a saber: el establecimiento de mecanismos de selección de candidatos para la formación docente, la adecuación de los contenidos de la formación inicial a la realidad práctica de la enseñanza, y la sustitución de los enfoques normativos por enfoques descriptivos en los planes de formación.

Sobre la base de consideraciones como las anteriores, y de acuerdo con el avance de la psicología cognitiva y el constructivismo, se vinieron a introducir nuevas perspectivas sobre la adquisición del conocimiento, lo que evidentemente impactó la educación de niños y jóvenes a la vez que impactaba los procesos de formación de sus profesores con una orientación más bien descriptiva. La formación del profesorado se basará en establecer estrategias de pensamiento y de percepción, paradigma centrado en la toma de decisiones que resalta la capacidad del docente para procesar, sistematizar y comunicar la información (Imbernón, 1994). Esta formación deberá facilitar la consecución de un conjunto de competencias genéricas para la ejecución del papel docente, la adquisición de destrezas no conductuales que posibiliten al profesor decidir sobre el comportamiento más adecuado dependiendo de la situación, y la capacitación del profesor para actuar como investigador en el aula con una visión crítica y constructiva del currículo. La diferencia sustantiva entre los enfoques normativos y descriptivos reside en que estos últimos buscan que, mediante la formación profesional, el educador pueda enfrentar su tarea problematizándola y, por lo tanto, buscando una resolución particular a cada hecho, y no aplicando indistintamente estrategias y procedimientos metodológicos a situaciones que pueden ser diferenciadas en cuanto a las características y necesidades de los sujetos de la intervención pedagógica. Los enfoques descriptivos poseen una fuerte influencia de la psicología cognoscitiva, en cuanto a que busca que el profesor pueda tomar en cuenta los conocimientos previos del estudiante en el desarrollo de los contenidos educativos, pueda motivar al estudiante a participar activamente en su proceso de aprendizaje; estimule la búsqueda del sentido de los conocimientos, y fomente el desarrollo de estrategias cognoscitivas para la exploración y el descubrimiento. Además es evidente la influencia de la psicología humanista puesto que buscan que los profesores puedan desarrollar un programa flexible para la incorporación de los intereses de los estudiantes, proporcionar recursos de aprendizaje de su experiencia personal y que fomenten el aprendizaje participativo y la autoevaluación (Rueda Beltrán y Díaz Barriga, 2000). En la práctica, si el profesor constatara un fracaso pensará que debe 
corregir su actuación estudiando la realidad en la que enseña, con el fin de responder adecuadamente a los elementos de una situación que no domina (Esteve, 1996).

Posteriormente surge el paradigma contextual o ecológico que enriquece el anterior al incluir necesariamente el estudio de la vida del estudiante en su contexto. Un aporte importante en este campo lo constituye el enfoque de la Ecología Humana de Bromfenbrenner de 1979 (Kasambira, 2000), enfoque que describe el ambiente que rodea al estudiante, como una serie de ecosistemas fluidos, dinámicos, interactivos y holísticos, denominados macrosistema (contexto cultural), exosistema (redes externas como medios de comunicación, espacios laborales, sistema educativo), mesosistema (escuela, familia, comunidad como entes en interacción), y microsistema (el aula, el hogar o la escuela). Estos ecosistemas se encuentran interconectados como un juego de muñecas rusas en vista de que el microsistema es envuelto y en cierta medida determinado por el mesosistema, éste a su vez por el exosistema, envolviéndolos todos el macrosistema. Esta consideración procura poner en armonía el quehacer docente con la realidad vital del estudiante puesto que ofrece ideas bastante objetivas de cómo interactúa con su ambiente, y de cómo responder apropiadamente a sus conductas y necesidades. Además, la interpretación del ambiente que rodea al educando permite determinar la pertinencia de sus conductas ya que existen puntos de referencia para valorar la calidad de su interacción con los demás. En definitiva, la comprensión de la ecología humana puede facilitar al profesorado actuar como profesionales que dan respuesta oportuna a las necesidades y derechos de los educandos, es decir, individualizar su intervención docente.

Con el propósito de desarrollar su concepción de formación del profesorado, Marcelo (1994) expone los principios que subyacen esta idea. Interesa destacar aquellos que reflejan una perspectiva no normativa y que enfocan la importancia de adecuar la tarea a la situación educativa que se enfrenta. La integración teoría práctica viene a ser uno de los elementos que permiten al educador enfrentar con mayor precisión y probabilidad de éxito su tarea docente al estimular la capacidad para la deliberación, la reflexión para la acción, y la apropiación de conocimiento práctico. Los profesores, como profesionales de la enseñanza, deben desarrollar un conocimiento propio para introducir en sus rutinas docentes y dar respuesta a las necesidades de cada estudiante, en cada lugar y en cada momento, de acuerdo con la problematización que ha hecho de su actuación profesional. Otro de los principios elaborados por este autor es el de la individualización. De acuerdo con lo expuesto 
anteriormente, se supone que aprender a enseñar no debe ser un proceso homogéneo para todos, sino que esta acción está determinada por las características personales, cognitivas, contextuales y relacionales, entre otras, de cada sujeto sometido a los procesos de formación profesional. Es decir, no sólo resulta de importancia mayor el trato individualizado que debe dar cada profesor a sus estudiantes y al contexto educativo, sino que es uno de los elementos que deben ser considerados también en los currículos universitarios. La formación del profesorado debe basarse en las necesidades e intereses de los participantes, adaptada al contexto en el que éstos trabajan, y fomentar la participación y reflexión.

En resumen, la formación de un profesor habría de partir de los problemas educativos de la práctica cotidiana o del ámbito escolar en el mundo actual y, al mismo tiempo, debe utilizar la teoría como instrumento para analizar y reflexionar sobre esa práctica (Blázquez Entonado, 1998). La interacción teoría práctica adquiere importancia central en los procesos de formación del profesorado, no así la adquisición de comportamientos y destrezas, ni la adopción de patrones de personalidad atribuibles a una idea preestablecida de maestro. La dimensión práctica no radica exclusivamente en la observación y participación de la dinámica educativa sino que hace falta desarrollar estrategias que permitan la reflexión sobre las realidades observadas, la acción a partir del análisis del contexto y la aplicación de teorías implícitas y explícitas. No existe el buen profesor definido por unas características de personalidad determinadas, ni un modelo de actuación único en el cual se explicita lo que el profesor debe hacer. Por el contrario, se constata la existencia de buenos profesores con rasgos de personalidad muy diversos, y de estilos diferentes, igualmente eficaces para afrontar una misma situación educativa (Esteve, 1996). Todo dependerá del enfoque pedagógico que asuman los formadores de docentes, todo dependerá del modelo que sustente el currículo para la formación de educadores.

\section{MÉTODO}

\section{a. Tipo de investigación.}

La investigación social cualitativa aborda el estudio de la construcción social de la realidad elaborada por los individuos, en sus actos de habla individuales y colectivos. La acción humana es siempre reflexiva y el contexto viene elaborado y dado en ella por lo que se despliega automáticamente en el habla (Noya, 1994). El método de investigación cualitativa busca la comprensión de los motivos y creencias que están detrás de las acciones o de las palabras de la gente. Entre sus principales características se destaca el hecho de que es 
inductiva, es decir, el investigador desarrolla conceptos, intelecciones y comprensiones partiendo de pautas de los datos, y no recogiendo datos para evaluar modelos, hipótesis o teorías preconcebidas. Además, para el investigador cualitativo todas las perspectivas son valiosas puesto que no busca la verdad sino una comprensión detallada de los puntos de vista de las personas. Se sustenta en el enfoque teórico de la fenomenología, puesto que el fenomenólogo quiere entender los fenómenos sociales desde la propia perspectiva del actor, y en el caso del presente trabajo, se sustenta en la escuela de pensamiento del interaccionismo simbólico, puesto que esta corriente atribuye una importancia primordial a los significados sociales que las personas asignan al mundo que las rodea, significados que están constantemente definiéndose a medida que pasan por situaciones diferentes, y a medida que se intercambian entre actores (Taylor y Bogdan, 1996). La realidad se encuentra en las percepciones de los sujetos, y la tarea del investigador es comprender y dilucidar su significado, para reconstruirlo, sin haber manipulado o controlado la conductas o ambientes de los sujetos participantes (McMillan, 1996).

El enfoque cualitativo es coherente con el propósito de este estudio en vista de que se busca elaborar la reproducción de un sentido social, el del buen maestro, con la participación de actores sociales afectados principalmente por la acción de este profesional quienes en conjunto dilucidan sus ideas o percepciones, y mediante una interpretación sistemática de sus aportaciones orales, de las cuales tanto lo incluido como lo excluido son elementos que contribuyen a la construcción del objeto en estudio.

\section{b. Técnica para la recolección de la información}

Los diversos modos de la expresividad humana se organizan como lenguajes, entendidos como sistemas de formas expresivas que pertenecen y configuran un cierto modo de expresividad humana (Navarro y Díaz, 1994). El lenguaje oral es uno de estos sistemas de formas expresivas y fue precisamente la forma escogida en este trabajo para recopilar la información y reflejar esta porción propia del tejido social referente a la idea del buen educador.

Por la naturaleza del propósito de este trabajo, se seleccionaron como técnica de recolección de la información, los Grupos de Discusión, definidos por Canales y Peinado (1994) como una técnica de investigación social que trabaja con el habla. En ella lo que se dice se asume como punto crítico en el que lo social se reproduce y cambia. En toda habla se articula el 
orden social y la subjetividad. El discurso social, la ideología en su sentido amplio no habita, como un todo, ningún lugar social en particular sino que aparece diseminado en lo social. El grupo de discusión equivale a una situación discursiva, y actúa como una retícula que fija y ordena, según criterios de pertinencia, el sentido social correspondiente, en este caso, a la idea de un buen maestro. Los grupos de discusión facilitan la escritura de la cultura en conjunto. Es una técnica colectiva que se concentra en la diversidad de actitudes, experiencias y creencias de los participantes de manera que esté mejor representada la cultura. La singularidad de esta técnica permite al investigador social observar el proceso sociológico más importante y la interacción colectiva entre seres humanos (Madriz, 2000).

La técnica de los grupos de discusión consiste en una entrevista a un grupo de personas, diseñada para promover la interacción entre los individuos, que lleva a una comprensión más rica del objeto de estudio. Un moderador guía la discusión que se basa en un tema preparado con anticipación, pero no de manera estructurada. Se busca más bien darle la oportunidad a los participantes de explicar sus puntos de vista, sus pensamientos y cómo interpretan y explican los acontecimientos que viven. Es decir, esta técnica es de gran utilidad para animar a las personas, mediante la interacción entre ellas, a que evidencien sus ideas y reflexiones acerca de un concepto, una idea, un valor o cualquier otro aspecto relacionado con su experiencia y su conocimiento (McMillan, 1996). La forma detallada de su aplicación será expuesta más adelante.

Para la escogencia de este tipo de entrevista grupal a profundidad, es decir, los grupos de discusión, fueron consideradas las condiciones planteadas por Taylor y Bogdan (1996). Se opta por entrevistar cuando los escenarios o las personas no son accesibles de otro modo. En este caso, sólo agrupando a los participantes iba a ser posible descubrir sus percepciones acerca de la idea de un buen maestro pues no es un sentimiento que pueda ser observado fácilmente en las conductas de las personas. Otra condición para optar por la entrevista es que la investigación dependa de una amplia gama de personas, elemento considerado en nuestro caso puesto que interesa construir un sentido colectivo con la participación de diferentes actores. Se debe considerar también que si el investigador desea esclarecer experiencias humanas subjetivas, lo ideal es recurrir a la entrevista aunque se corra el riesgo de las falsificaciones, los engaños, las exageraciones o las distorsiones de los hablantes. Estas limitaciones se resuelven apropiadamente aplicando un método riguroso de análisis de la información. 


\section{c. Técnica para el análisis de la información}

En vista de que se contaría con información recolectada mediante grupos de discusión, fue necesario elegir un método y una técnica cualitativas que permitieran el establecimiento del sentido social que se buscaba. Esta tarea interpretativa se realizó mediante el método de análisis de contenido. Este método se origina como análisis documental aplicado de manera primigenia en la investigación histórica, ampliándose su aplicación a la investigación descriptiva de hechos o situaciones de vigencia actual (Van Dalen y Meyer, 1971). Si bien en sus orígenes el análisis de documentos buscaba la descripción de hechos sin intención de analizar más allá de lo observado en estos textos, a partir de 1950 en el campo de la educación se inició la búsqueda, mediante la aplicación de este método, de factores cualitativos de importancia no sólo en documentos existentes, sino en documentos producidos para efectos específicos, como son las transcripciones de entrevistas a profundidad. Cuando se lleva a cabo este tipo de estudios cualitativos, el investigador se preocupa relativamente menos por el contenido como tal, que por éste como reflejo de fenómenos más profundos. De acuerdo con estos autores, el método tiene grandes ventajas, entre las que interesa destacar que puede ayudar a los educadores a describir costumbres y requerimientos específicos de la escuela y la sociedad, descubrir las tendencias existentes, e identificar los prejuicios, actitudes, intereses, o estados psicológicos de las personas.

El análisis de los datos es un proceso dinámico y creativo. Se trata de obtener una comprensión más profunda de lo que se estudia, y se continúan refinando las interpretaciones para llegar al sentido de los fenómenos. Básicamente, el análisis de los datos implica tres etapas bien diferenciadas (Taylor y Bogdan, 1996). La primera es la fase de descubrimiento en progreso para identificar temas y desarrollar conceptos y proposiciones. La segunda incluye la codificación de los datos y el refinamiento de la comprensión del tema en estudio. En la tercera se trata de la relativización de los descubrimientos mediante la comprensión de los datos en el contexto en que fueron recogidos, ya sea el contexto de los participantes de la investigación, o el contexto metodológico del trabajo. En síntesis, se descubren, se codifican y se relativizan los datos.

Para cumplir con esta tarea, como técnica específica se aplicó el análisis de contingencias. Esta técnica aborda el hecho de la significación desde un punto de vista relacional, cooperativo y cualitativo. Lo que esta perspectiva trata de investigar primordialmente son las 
relaciones de asociación o la presencia concurrente, dentro de un determinado contexto, de las unidades significativas (Navarro y Díaz, 1994). En vista de que el propósito de este estudio es elaborar un sentido social, es obvio entonces que este sentido se fundamente en las ideas concurrentes y comunes entre diferentes sujetos sociales. De manera detallada, en la parte de los resultados se describirá la forma en que fue aplicada esta técnica.

\section{d. Selección de los participantes.}

Las entrevistas cualitativas requieren un diseño flexible de la investigación. Ni el número ni el tipo de informantes se especifica de antemano. El investigador comienza con una idea general sobre las personas que entrevistará y el modo de encontrarlas, pero está dispuesto a cambiar el curso en caso necesario (Taylor y Bogdan, 1996)). No se trata de entrevistar a muchas o pocas personas, o de elaborar un muestreo significativo de sujetos, ni mucho menos buscar tal representatividad que permita la generalización puesto que en investigación cualitativa lo que se retrata es sólo una porción de la realidad. Se recomienda, y fue lo aplicado en este caso, utilizar la técnica del muestreo teórico que indica que el número de "casos" estudiados carece relativamente de importancia, sino más bien el potencial de cada "caso" como medio para la comprensión teórica del problema en estudio.

Para la reproducción de la idea del buen maestro resulta conveniente involucrar como actores importantes a quienes se ven directamente involucrados con ella, pero sin ser directamente responsables o reflejo de esta concepción ideológica para garantizar mayor autenticidad en las expresiones orales. Como plantean Canales y Peinado (1994), las relaciones comunicables en un grupo de discusión son aquellas que socialmente se comunican de hecho, y no aquellas no comunicables por razones de exclusión, de polos antagónicos en el discurso. En estos casos, los representantes de un grupo subordinado se abstienen de opinar o se adhieren al discurso de los dominantes.

Considerando lo anteriormente planteado, se conformaron los siguientes grupos de discusión:

- Un grupo de 4 niños y 2 niñas estudiantes de primaria, con edades entre 9 y 11 años. Aunque el grupo pudo haber tenido más participantes, se consideró oportuno trabajar con pocos para darles oportunidad, primero, de conocerse y establecer relaciones comunicables, y facilitar el surgimiento de sus percepciones. Se definió tal rango de edad para hacer efectiva la participación de todos en medio de un lenguaje y experiencias comunes. 
- Un grupo de 4 padres y 4 madres de familia sin relación entre si, con hijos en educación primaria y secundaria. En este caso se consideró importante contar con hombres y mujeres en igual número con el propósito de equilibrar el aporte conceptual de acuerdo con el rol que cada uno de ellos cumple en la familia.

- Un grupo de 2 profesores y 3 profesoras formadores de educadores de la Universidad de Costa Rica y de la Universidad Estatal a Distancia. En este caso no se controló directamente la participación de estos docentes, sino que se hizo una invitación abierta a los profesores de ambos departamentos, y esa fue la respuesta. Aunque los formadores de educadores pueden ser considerados indirectamente corresponsables de las actuaciones de estos profesionales, se consideró pertinente su participación en el estudio al estar fundamentado en una teoría de enfoques de formación inicial de docentes.

A la hora de conformar estos grupos se tomó en cuenta que no era conveniente que se conocieran entre si, pues el grupo no puede preexistir en el momento de la producción del texto, ni en él deben verse huellas de relaciones anteriores. Por lo tanto la investigadora aprovechó sus redes sociales tales como parientes, amigos, vecinos, compañeros de trabajo, pero diversificándolas. Sin embargo entre el grupo de formadores de educadores existían conexiones laborales imposibles de evitar, por lo que la investigadora procuró que se hiciera explícita la información compartida, a todos los miembros del grupo. Esta fue una de las razones por las que esta discusión con este grupo se prolongó durante mucho más tiempo.

\section{e. Estrategia para la aplicación de los grupos de discusión}

Siguiendo los lineamientos de Canales y Peinado (1994) el procedimiento aplicado fue el siguiente:

- Para realizar las reuniones con estudiantes de primaria y con padres y madres de familia, se utilizó una sala de reuniones existente en la Universidad de Costa Rica pues este espacio cumplía con la condición de ser un espacio neutral que no condicionaba el discurso de los participantes como lo haría el espacio de una escuela o colegio. Para realizar la reunión con los profesores universitarios, se utilizó una sala del Consejo Nacional de Rectores, instancia que agrupa a las universidades estatales costarricenses, por ser el lugar común de encuentro entre académicos de estas instituciones.

- Las discusiones fueron grabadas en cinta magnetofónica pues es el elemento al que están más familiarizados o el que causa menos distracción, en comparación con una cámara de 
video. A la vez la investigadora iba tomando nota de las ideas que se iban exponiendo sin indicar quién las exponía sino más bien, cuáles se constituían en consensos.

- La duración de cada reunión de los grupos varió dependiendo de la edad de los participantes, el criterio de saturación a lo interno de la discusión, y el interés mostrado por los participantes. La sesión con niños tuvo una duración de 40 minutos, con los padres y madres de familia tuvo una duración de 1 hora y 10 minutos, y con los formadores de educadores, 2 horas y 20 minutos.

- La investigadora fue una integrante del grupo con el propósito exclusivo de dinamizar la discusión y estimular la búsqueda de consensos, por lo que se constituyó en una observadora externa que no emitió juicios que determinaran u orientaran el contenido de la discusión, sino sólo la dinámica.

- De acuerdo con los objetivos de este trabajo, los temas que orientaron los grupos de discusión fueron los siguientes:

- Definición de las prácticas docentes más comunes desde la perspectiva de los participantes de cada grupo.

- Efectos que se perciben de esas prácticas docentes sobre el aprendizaje.

- Condiciones ideales de una buena práctica docente.

- Caracterización de un buen maestro.

\section{PROCEDIMIENTO PARA EL ANÁLISIS DE LA INFORMACIÓN Y RESULTADOS}

Por la naturaleza del estudio, a continuación se hará una descripción detallada de la forma en que se aplicó el análisis de contingencias, a la par de los resultados que se iban obteniendo. Esta técnica llega a concretarse mediante las orientaciones teóricas de Navarro y Díaz (1994) y Taylor y Bogdan (1996)

\section{a. Reelaboración del texto al cual se le aplicaría el análisis de contingencias.} Las expresiones orales originadas en los grupos de discusión fueron anotadas por la investigadora mientras se desarrollaba la interacción, y eran grabadas. Con estos materiales en mano, fue aplicado el criterio de convergencia considerando que, por la naturaleza de la técnica utilizada para recoger la información,

...todo lo que pueda haber de singular en un yo, no interesa a la investigación sociológica; lo que buscamos ... es trazar la topología de ese campo de convergencia 
imaginario ... dar cuenta de la constitución de ese campo de certezas ideológicas y, por lo tanto, sociales... (Canales y Peinado 1994, p. 294).

Es decir, lo que conformaría el texto serían las expresiones orales que mostraban puntos de vista coincidentes entre los participantes, o aquellas construidas en conjunto por los participantes. No conformaron parte del cuerpo de la información por analizar algunos aspectos que fueron "retirados" de la discusión por la falta de acuerdo o porque fueron mejor parafraseados o reconstruidos. Si bien es cierto lo incluido es tan importante como lo excluido mediante el habla, debe recordarse que no se trataba de entrevistas individuales sino colectivas, y tanto lo incluido como lo excluido debía ser producto de la convergencia entre participantes; por ejemplo, un buen maestro es..., un buen maestro no es...

La acción concreta realizada consistió en que los apuntes tomados por la investigadora durante los grupos de discusión, fueron analizados en busca de tales coincidencias, y enriquecidos con aquellos detalles de las grabaciones que no aparecían en los textos escritos. El texto escrito y el texto hablado dieron origen a un texto básico para ser sometido al análisis de contingencias.

\section{b. Descubrimiento en progreso.}

Para identificar temas y desarrollar conceptos y proposiciones, fue necesario leer repetidamente los datos; darle continuidad a los temas, intuiciones, interpretaciones e ideas; buscar temas emergentes; elaborar tipologías; y recurrir al marco teórico para refrescar conceptos. Producto de esta actividad fue posible enunciar los temas relevantes del texto, relacionados con el problema de la investigación, es decir, aquellos que definían características del buen maestro. Inicialmente fueron identificados alrededor de 40 temas, enunciados sin ningún orden o condición homogénea de redacción, y teniendo siempre el cuidado de no forzar datos para que encajaran en el marco teórico personal, o en marcos de conveniencia estética u operativa.

\section{c. Codificación.}

La codificación es un modo sistemático de desarrollar y refinar las interpretaciones de los datos. El proceso de codificación incluye la reunión y análisis de todos los datos para que, lo que inicialmente fueron ideas e intuiciones vagas, se refinen, se expandan, se descarten o se desarrollen por completo. En este caso fueron desarrolladas categorías de codificación redactando una lista de todos los temas y aportando, a la par de cada uno, las referencias textuales que justificaban la existencia del tema. En la investigación cualitativa no hay líneas guías que determinen la 
cantidad de datos necesarios para refrendar una interpretación, más bien queda sujeto al juicio del investigador. La mejores aprehensiones no siempre provienen de una gran cantidad de datos, sino que a veces es suficiente un único incidente para desarrollar una categoría conceptual. Producto del análisis anterior, la información finalmente fue organizada en 22 temas a los que, ya organizados de esta manera, se les dio el nombre de unidades de registro, es decir, las unidades básicas de relevancia, de significación.

Para presentar esta información, se elaboró un cuadro resumen que contenía tres columnas, en la primera se enuncia la característica deseada del buen maestro, en la segunda las intervenciones referentes a ésta, extraídas del texto de los grupos de discusión, y la identificación de la proveniencia del comentario. La tercera se reservó para indicar el número de referencias y el número de grupos en que aparecieron estas referencias. Las unidades de registro que reflejaban condiciones del maestro ideal se presentan en términos de características positivas o deseables, definidas por los participantes. Estas son:

1. Establece límites, disciplina: 9 referencias y presente en 1 grupo.

2. Se identifica con los estudiantes, maestro que es sensible a sus necesidades: 5 referencias y presente en dos grupos.

3. Conoce a los estudiantes, identificar fortalezas y condiciones personales para el aprendizaje: 14 referencias y presente en 3 grupos.

4. Es abierto, consideración del punto de vista de los otros: 9 referencias y presente en 3 grupos.

5. Tiene una visión integral del acto educativo, amplitud programática, visión global, formación humanística: 7 referencias y presente en 3 grupos.

6. Marca el futuro de los estudiantes, función determinante en la vida de los estudiantes: 5 referencias y presente en 1 grupo.

7. Tiene vocación, inclinación fuerte hacia la educación: 12 referencias y presente en 2 grupos.

8. Es bondadoso, que procura el bienestar de los estudiantes: 5 referencias y presente en 3 grupos.

9. Posee una imagen física apropiada, presentación personal y formas de comunicación socialmente aceptadas: 5 referencias y presente en 2 grupos.

10. Propicia la autoaceptación de los estudiantes, estima propia de los estudiantes: 5 referencias y presente en 2 grupos.

11. Tiene conocimiento del contexto actual, condiciones relacionadas con la sociedad en la que se desarrolla el acto educativo: 12 referencias y presente en 2 grupos.

12. Es flexible, capaz de realizar los ajustes necesarios para resolver problemas: 5 referencias y presente en 3 grupos.

13. Es un profesional, conocimientos, habilidades y destrezas aprendidas para llevar a cabo la tarea educativa: 27 referencias y presente en 3 grupos. 
14. Comprende la relación hogar escuela, identificación y diferenciación del rol de cada uno de estos ambientes en la educación: 5 referencias y presente en 2 grupos.

15. Es persona de buen trato, amable, accesible, respetuoso: 10 referencias y presente en 3 grupos.

16. Es mediador, que no enseña sino que propicia el aprendizaje: 1 referencia y presente en 1 grupo.

17. Es investigador, que fundamenta su práctica educativa en actividades de investigación: 5 referencias y presente en 1 grupo.

18. Tiene sensibilidad social, que conoce y asume el compromiso con el mejoramiento social: 2 referencias y presente en 1 grupo.

19. Es innovador, que resuelve la tarea educativa en forma creativa y pertinente: 3 referencias y presente en 1 grupo.

20. Es un profesional autoafirmado, que se siente orgulloso y satisfecho con su rol social de educador: 4 referencias y presente en 1 grupo.

21. Es moral, que vive conforme a los principios morales que orientan la sociedad: 7 referencias y presente en 1 grupo.

22. Es responsable de su tarea, que no supedita la efectividad de sus acciones a lo que sucede en el contexto: 2 referencias y presente en 1 grupo.

Obsérvese que la unidad de registro con mayor cantidad de referencias es la denominada "Es profesional" con 27, seguida por "Conoce a los estudiantes" con un número bastante inferior, 14. Similares a esta última, con 12 referencias cada una, se encuentran "Tiene vocación" y "Conoce el contexto actual", y "Es persona de buen trato" con 10 referencias. Las restantes unidades de registro fueron construidas con menos de 10 referencias cada una. Es decir, el tema que fue discutido con mayor frecuencia es el relacionado con las condiciones profesionales del educador y este mismo fue discutido en los tres diferentes grupos de discusión, lo que le otorga la categoría de tema de relevancia mayor en esta fase del estudio. En segundo lugar se destaca como buen maestro el que conoce a sus estudiantes pues también fue discutido en los tres grupos. Puede observarse que algunos temas discutidos con baja frecuencia, estuvieron presentes en los tres grupos, como por ejemplo "Es flexible" y "Es bondadoso", lo que quiere decir que existe entre los integrantes de los tres grupos una preocupación por tales condiciones, pero no constituyeron un tema central. Otras condiciones tienen una importancia menor como es el caso de aquellas con muy pocas referencias y discutidas en un solo grupo. 


\section{d. Relativización de los datos.}

Para entender los datos hay que detenerse a analizar el contexto en que fueron recogidos, o los supuestos teóricos o metodológicos que condicionan el estudio. Estos elementos contextuales están definidos desde el problema de la investigación, y sustentados en los referentes teóricos del trabajo. Nos referimos a la interpretación que puede surgir de la aplicación de los enfoques normativo y descriptivo para la formación de educadores, a las características del buen maestro extraídas del habla de los participantes.

La discusión de cada uno de estos temas no estuvo orientada por uno solo de los enfoques teóricos que sustentan este estudio, es decir, el normativo y el descriptivo, sino que en casi todas las unidades de registro se encontraban referencias pertenecientes a las dos, por lo que esta codificación sólo podía hacerse evidente mediante la creación de las unidades de contexto y la adscripción de todas y cada una de las unidades de registro a ellas.

Una unidad de contexto se puede crear a partir de la identificación de elementos que se presentan con mayor intensidad y con una orientación conceptual clara, para que los significados de las unidades de registro sean referidos a los lugares concretos del texto en los que aparecen. O bien, como en el caso que nos ocupa, una unidad de contexto es un marco interpretativo más restringido que el corpus en su totalidad, que da relevancia a las unidades de registro dentro de un criterio extratextual. Estas unidades están enmarcadas en el sustento teórico y metodológico del trabajo, y están referidas directamente al problema de la investigación (Navarro y Díaz, 1994). Para determinar las unidades de contexto en este caso, como se mencionó, se tomaron en consideración el problema de la investigación y el sustento teórico de este trabajo, creándose dos tipos de unidades de contexto, las referidas a los enfoques normativos para la formación de educadores, y las referidas a los enfoques descriptivos. Cada unidad de contexto corresponde a un indicador o componente de los enfoques, obteniéndose lo siguiente:

\begin{tabular}{|l|l|}
\hline Enfoque Normativo & Enfoque descriptivo \\
\hline 1. Tiene personalidad de educador & $\begin{array}{l}\text { 1. Desarrolla y aplica estrategias de } \\
\text { pensamiento }\end{array}$ \\
\hline 2. Posee destrezas de educador & $\begin{array}{l}\text { 2. Desarrolla y aplica estrategias de } \\
\text { percepción u observación }\end{array}$ \\
\hline
\end{tabular}




\begin{tabular}{|l|l|}
\hline 3. Practica conductas de educador & $\begin{array}{l}\text { 3. Desarrolla capacidad para la toma de } \\
\text { decisiones }\end{array}$ \\
\hline & 4. Sabe considerar el contexto \\
\hline & 5. Puede individualizar la tarea \\
\hline
\end{tabular}

Para referir o relativizar la información, en cada unidad de contexto se incluyeron las unidades de registro en las que aparecían referencias relacionadas con cada una de ellas. Es decir, las unidades de registro detectadas en el corpus textual fueron adscritas a sus respectivas unidades de contexto. Una vez realizada esta tarea, era necesario cuantificar la frecuencia de aparición de referencias relacionadas con un enfoque, y medir el nivel de concurrencia, es decir, si habían sido emitidas por uno, dos o los tres grupos de participantes.

El resultado de esta tarea se muestra en la siguiente matriz:

Matriz de unidades de registro referidas a las unidades de contexto

\begin{tabular}{|c|c|c|c|}
\hline $\begin{array}{lr}\text { Unidades } & \text { de } \\
\text { contexto } & o \\
\text { indicadores } & \text { de } \\
\text { enfoque } & \end{array}$ & $\begin{array}{l}\text { Unidades de registro o } \\
\text { condiciones del buen } \\
\text { maestro }\end{array}$ & $\begin{array}{l}\text { Frecuencia } \\
\text { de aparición } \\
\text { de } \\
\text { referencias }\end{array}$ & $\begin{array}{l}\text { Intensidad } \\
\text { 1- Estudiantes } \\
\text { 2- Padres } \\
\text { 3- Formadores }\end{array}$ \\
\hline $\begin{array}{l}\text { Tiene personalidad } \\
\text { de maestro }\end{array}$ & $\begin{array}{l}\text { 1. Tiene vocación } \\
\text { 2. Es profesional } \\
\text { 3. Es moral } \\
\text { 4. Influencia el futuro } \\
\text { 5. Es bondadoso } \\
\text { 6. Da buen trato } \\
\text { 7. Profesional autoafirmado } \\
\text { 8. Establece límites } \\
\text { 9. Es flexible } \\
\text { 10. Es abierto }\end{array}$ & $\begin{array}{l}10 \\
8 \\
6 \\
5 \\
4 \\
4 \\
3 \\
2 \\
1 \\
1\end{array}$ & $\begin{array}{l}\text { Mediana (2-3) } \\
\text { Alta (1-2-3) } \\
\text { Baja (3) } \\
\text { Baja (2) } \\
\text { Alta (1-2-3) } \\
\text { Alta (1-2-3) } \\
\text { Baja (3) } \\
\text { Baja (2) } \\
\text { Alta (1-2-3) } \\
\text { Alta (1-2-3) }\end{array}$ \\
\hline Tiene destrezas de & 1. Es profesional & 8 & Alta (1-2-3) \\
\hline
\end{tabular}




\begin{tabular}{|c|c|c|c|}
\hline $\begin{array}{lr}\text { Unidades } & \text { de } \\
\text { contexto } & o \\
\text { indicadores } & \text { de } \\
\text { enfoque } & \end{array}$ & $\begin{array}{l}\text { Unidades de registro } 0 \\
\text { condiciones del buen } \\
\text { maestro }\end{array}$ & $\begin{array}{l}\text { Frecuencia } \\
\text { de aparición } \\
\text { de } \\
\text { referencias }\end{array}$ & $\begin{array}{l}\text { Intensidad } \\
\text { 1- Estudiantes } \\
\text { 2- Padres } \\
\text { 3- Formadores }\end{array}$ \\
\hline $\begin{array}{l}\text { maestro } \\
9 \text { referencias }\end{array}$ & 2. Establece límites & 1 & Baja (2) \\
\hline $\begin{array}{l}\text { Practica conductas } \\
\text { de maestro }\end{array}$ & $\begin{array}{l}\text { 11. Da buen trato } \\
\text { 12. Imagen física } \\
\text { 13. Relación hogar escuela. } \\
\text { 14. Es flexible } \\
\text { 15. Es profesional } \\
\text { 16. Propicia autoaceptación } \\
\text { 17. Tiene sensibilidad social } \\
\text { 18. Establece límites } \\
\text { 19. Es bondadoso } \\
\text { 20. Conoce a los estudiantes } \\
\text { 21. Conoce contexto actual }\end{array}$ & $\begin{array}{l}5 \\
5 \\
3 \\
2 \\
2 \\
2 \\
1 \\
1 \\
1 \\
1 \\
1\end{array}$ & $\begin{array}{l}\text { Mediana (1-3) } \\
\text { Mediana (1-2) } \\
\text { Baja (2) } \\
\text { Mediana (1-2) } \\
\text { Baja (2) } \\
\text { Baja (1) } \\
\text { Baja (3) } \\
\text { Baja (2) } \\
\text { Baja (1) } \\
\text { Baja (1) } \\
\text { Baja (2) }\end{array}$ \\
\hline $\begin{array}{l}\text { Desarrolla y aplica } \\
\text { estrategias de } \\
\text { pensamiento } \\
32 \text { referencias }\end{array}$ & $\begin{array}{l}\text { 1. Conoce a los estudiantes } \\
\text { 2.Es profesional } \\
\text { 3. Es investigador } \\
\text { 4. Establece límites } \\
\text { 5. Es innovador } \\
\text { 6. Conoce el contexto actual } \\
\text { 7. Se identifica con los est. } \\
\text { 8. Es mediador } \\
\text { 9. Tiene visión in. acto educ. } \\
\text { 10. Tiene vocación }\end{array}$ & $\begin{array}{l}8 \\
6 \\
5 \\
4 \\
2 \\
2 \\
2 \\
1 \\
1 \\
1\end{array}$ & $\begin{array}{l}\text { Mediana (2-3) } \\
\text { Alta (1-2-3) } \\
\text { Baja (3) } \\
\text { Baja (2) } \\
\text { Baja (3) } \\
\text { Baja (3) } \\
\text { Baja (2) } \\
\text { Baja (3) } \\
\text { Baja (2) } \\
\text { Baja (3) }\end{array}$ \\
\hline $\begin{array}{l}\text { Desarrolla y aplica } \\
\text { estrategias } \\
\text { percepción } \\
\text { observación }\end{array}$ & $\begin{array}{l}\text { 1. Es abierto } \\
\text { 2. Se identifica con los est. } \\
\text { 3. Propicia autoaceptación } \\
\text { 4. Tiene visión in. acto educ. }\end{array}$ & $\begin{array}{l}4 \\
3 \\
3 \\
2\end{array}$ & $\begin{array}{l}\text { Alta (1-2-3) } \\
\text { Mediana (2-3) } \\
\text { Baja (2) } \\
\text { Baja (2) }\end{array}$ \\
\hline
\end{tabular}




\begin{tabular}{|c|c|c|c|}
\hline $\begin{array}{lr}\text { Unidades } & \text { de } \\
\text { contexto } & o \\
\text { indicadores } & \text { de } \\
\text { enfoque } & \end{array}$ & $\begin{array}{l}\text { Unidades de registro o } \\
\text { condiciones del buen } \\
\text { maestro }\end{array}$ & $\begin{array}{l}\text { Frecuencia } \\
\text { de aparición } \\
\text { de } \\
\text { referencias }\end{array}$ & $\begin{array}{l}\text { Intensidad } \\
\text { 1- Estudiantes } \\
\text { 2- Padres } \\
\text { 3- Formadores }\end{array}$ \\
\hline 18 referencias & $\begin{array}{l}\text { 5. Es profesional } \\
\text { 6. Tiene sensibilidad social } \\
\text { 7. Conoce a los estudiantes } \\
\text { 8. Da buen trato } \\
\text { 9. Es profesional autoafirm. }\end{array}$ & $\begin{array}{l}2 \\
1 \\
1 \\
1 \\
1\end{array}$ & $\begin{array}{l}\text { Baja (3) } \\
\text { Baja (3) } \\
\text { Baja (2) } \\
\text { Baja (1) } \\
\text { Baja (3) }\end{array}$ \\
\hline $\begin{array}{l}\text { Desarrolla } \\
\text { capacidad para la } \\
\text { toma de decisiones }\end{array}$ & $\begin{array}{l}\text { 1. Es responsable de su } \\
\text { tarea } \\
\text { 2. Es flexible } \\
\text { 3. Es abierto } \\
\text { 4. Es profesional } \\
\text { 5. Tiene vocación } \\
\text { 6. Establece límites }\end{array}$ & $\begin{array}{l}2 \\
2 \\
1 \\
1 \\
1 \\
1\end{array}$ & $\begin{array}{l}\text { Baja (3) } \\
\text { Baja (3) } \\
\text { Baja (3) } \\
\text { Baja (3) } \\
\text { Baja (3) } \\
\text { Baja (2) }\end{array}$ \\
\hline $\begin{array}{l}\text { Sabe considerar el } \\
\text { contexto } \\
15 \text { referencias }\end{array}$ & $\begin{array}{l}\text { 1. Conoce contexto actual } \\
\text { 2. Tiene visión in. acto educ. } \\
\text { 3. Comprende relación H-E } \\
\text { 4. Conoce a los estudiantes } \\
\text { 5. Es abierto } \\
\text { 6. Es profesional }\end{array}$ & $\begin{array}{l}7 \\
3 \\
2 \\
1 \\
1 \\
1\end{array}$ & $\begin{array}{l}\text { Mediana (2-3) } \\
\text { Mediana (1-3) } \\
\text { Mediana (2-3) } \\
\text { Baja (3) } \\
\text { Baja (3) } \\
\text { Baja (3) }\end{array}$ \\
\hline $\begin{array}{l}\text { Puede } \\
\text { individualizar } \\
\text { tarea } \\
6 \text { referencias }\end{array}$ & $\begin{array}{l}\text { 1. Conoce a los estudiantes } \\
\text { 2. Es abierto } \\
\text { 3. Tiene visión in. acto educ. }\end{array}$ & $\begin{array}{l}3 \\
2 \\
1\end{array}$ & $\begin{array}{l}\text { Mediana (1-3) } \\
\text { Baja (1) } \\
\text { Baja (2) }\end{array}$ \\
\hline
\end{tabular}

La matriz está constituida por cuatro columnas en las cuales se sintetiza el trabajo de relativización realizado. En la primera se enuncian las unidades de contexto que son los indicadores o categorías de los enfoques normativo y descriptivo que se utilizan en el presente estudio para explicar las preferencias ideológicas de los participantes de este estudio con respecto a la idea del buen maestro. Los tres primeros escritos con letra itálica, 
se refieren al enfoque normativo, y los cinco restantes al enfoque descriptivo. Se indica en cada uno de los indicadores el número de referencias encontradas. En la segunda columna se exponen las unidades de registro, condiciones o características del buen maestro en las que se encontraron las referencias que se explican a partir de los indicadores de cada enfoque. Nótese que varias de las unidades de registro se encuentran en diferentes unidades de contexto puesto que eran las que contenían referencias relativas a los dos enfoques. En la tercera columna se especifica el número de referencias de cada condición. En la cuarta columna se consigna si el tema de la unidad de registro fue discutido en uno, en dos o en tres de los grupos (baja, mediana, alta), y entre paréntesis se indica el número del grupo (1- estudiantes; 2- padres de familia; 3- profesores universitarios). Se anotan de primeros aquellos temas presentados con mayor frecuencia. En síntesis, con estas dos columnas se puede determinar el predominio de enfoque en la construcción del sentido social de la idea de un buen maestro.

\section{DISCUSIÓN DE LOS RESULTADOS}

A continuación se examinará el contenido de cada una de las unidades de contexto, aprovechando las referencias que dieron origen a las unidades de registro, y se definirá el nivel de predominio de cada uno de estos temas en la idea propósito de este estudio.

\section{a. Personalidad (tendencias afectivas y conductuales que determinan al educador)}

De las diez condiciones de personalidad del maestro ideal indicadas por los participantes, se destacan por tener las frecuencias mayores tiene vocación, es profesional, es moral y marca positivamente el futuro del estudiante. Sin embargo, sólo el profesionalismo tiene la característica de ser la condición concurrente en los tres grupos de discusión. Las restantes seis condiciones tienen frecuencias bajas, pero cuatro de ellas también presentan el grado mayor de concurrencia (es bondadoso, da buen trato, es flexible y es abierto). Como condiciones presentes pero sin dárseles mayor importancia, se encuentran es un profesional autoafirmado como componente de la identidad propia, y establecen límites por medio de mecanismos personales inspiradores más que formadores.

De estas tendencias afectivas y conductuales que determinan a un educador según los participantes en este estudio, puede decirse que para todos, el ser profesional como actitud componente de la personalidad, es la condición a la que mayor importancia se le dio en el marco del presente trabajo. De acuerdo con las referencias de los participantes, esta 
condición es entendida como dinamismo, capacidad y poder de comunicación. Tiene vocación fue tema concurrente entre padres de familia y formadores de educadores, y se define como mística, como una forma diferente de enfrentarse a una tarea teniendo en consideración valores superiores más allá de la conveniencia personal. En cuanto a es moral, este fue un tema discutido con alguna amplitud pero exclusivamente por parte de los formadores de educadores quienes enfatizaron en la importancia de que el maestro viva los valores que predica. Una de las preocupaciones mayores de los padres de familia fue el hecho de que consideraban que el maestro de los primeros años escolares, necesariamente dejaba una huella que no se borraba fácilmente, por lo que definieron como proyección de su personalidad, la idea que el niño se hace de la escuela para toda la vida.

De las condiciones de personalidad de más baja frecuencia resulta interesante observar aquellas que fueron traídas a la discusión por los tres grupos, como es bondadoso y da buen trato, condiciones relacionadas con formas de relacionarse, y es flexible y es abierto, condiciones relacionadas con el respeto a los demás. Parece ser que se valora mucho la construcción de ambientes escolares en los que prevalezca la paz y el entendimiento entre todos, aunque no se enfatice con mayor frecuencia.

La personalidad del maestro, componente de los enfoques normativos para la formación de educadores, es uno de los temas con que es posible explicar una buena porción de la preferencia ideológica de los participantes de los grupos de discusión puesto que abarca la mayor cantidad de referencias que representan 10 diferentes condiciones de esta idea construida socialmente.

b. Destrezas (habilidades especiales aprendidas mediante la formación y la práctica) Esta categoría o indicador del enfoque normativo posibilita una escasa explicación de los resultados de este estudio puesto que fue construida por 9 referencias y 2 unidades de contexto, es profesional y establece límites. Nuevamente la condición profesional del educador viene a ser tema de gran interés puesto que además de que contiene la mayoría de las referencias encontradas, la destreza profesional fue considerada en los tres grupos de discusión. Como habilidades especiales aprendidas mediante la formación y la práctica, evaluar apropiadamente, trasmitir el contenido, saber enseñar, en fin, poseer destrezas docentes, son componentes importantes en la idea de buen maestro, lo que viene a abonar al interés general por la perspectiva normativa. 
c. Conductas (acciones específicas en respuesta a estímulos específicos)

Ninguna de las condiciones ideales del buen maestro asociadas a sus conductas y referidas por los participantes, fue tema concurrente en los tres grupos de discusión. Este indicador o categoría fue construido por 11 indicadores y 23 referencias, pero en la mayoría de los casos fueron producto de sólo un grupo. Sólo da buen trato fue tema de interés de los estudiantes y los formadores de educadores. Posee una imagen física apropiada fue producto de la discusión de estudiantes y padres de familia al igual que es flexible.

El buen trato se refleja en conductas como cumplir promesas siempre, no cometer injusticias, ofrecer afecto a los estudiantes, reconocer errores ante los demás, entre otras. La ropa que se usa y el vocabulario apropiado son ejemplos de la imagen física que se espera proyecte el maestro ideal. La flexibilidad se concreta en las oportunidades de escogencia que le brinda el buen maestro a sus estudiantes, y conductas tolerantes ante el mal comportamiento en la clase.

El componente conductas no parece ser entonces un elemento que contribuya de manera sustantiva a la explicación de la idea de buen maestro desde la perspectiva normativa, de acuerdo con las participaciones encontradas.

\section{d. Estrategias de pensamiento (capacidad de razonamiento)}

Este indicador de los enfoques descriptivos ofrece una explicación bastante amplia de los elementos que constituyen la idea del buen maestro. Está constituido por 32 referencias y 10 condiciones. Sin embargo, con relación al análisis anterior de las tres categorías normativas, no logra tener un nivel de concurrencia similar entre los tres grupos de discusión, a excepción del tema es profesional. Con una frecuencia de seis referencias y en palabras de los tres grupos, la condición profesional del maestro ideal fue descrita como capacidad de razonamiento para la aplicación de criterios relacionados con la asignación de trabajos a los estudiantes, y la aplicación de técnicas y estrategias de enseñanza; la concepción del acto educativo como un acto de mediación pedagógica; y la condición de profesional más alfabetizado.

Como contribución de los padres de familia y formadores de educadores, conoce a los estudiantes es la condición que con mayor frecuencia refieren dentro de esta categoría. 
Producto de diferentes estrategias de pensamiento, se espera que el buen maestro sepa identificar las fortalezas y debilidades de sus estudiantes al igual que detectar sus necesidades, y construir su acción docente de acuerdo con los diferentes estilos de aprendizaje. El ser investigador es una condición que sólo fue referida por los profesores universitarios, con una frecuencia tal que la ubica en tercer lugar. Así la duda razonable, el uso pertinente y discriminado de teorías pedagógicas, y la actitud crítica, son criterios que describen la idea que tienen del buen maestro. En cuanto a establece de límites, este tema fue del interés exclusivo de los padres familia como estrategia de pensamiento. Se describe como la aplicación razonable de medidas y sanciones que contribuyan con la disciplina en el aula, dentro de un marco de pertinencia y autoridad constructiva.

Casi la totalidad de estas condiciones fueron extraídas de las discusiones entre padres de familia y entre formadores de educadores. La participación de los escolares se observa exclusivamente en una de ellas, por lo que no parece que sea un tema que desde la perspectiva de este grupo, defina al maestro ideal.

e. Estrategias de percepción u observación (capacidad de discernimiento que facilita la comprensión del contexto)

Construido a partir de 18 referencias relacionadas con 9 condiciones ideales, y mediante la participación mayoritaria de padres de familia y formadores de educadores, este indicador del enfoque descriptivo de formación de educadores ocupa un lugar de importancia en la explicación de la elaboración de la idea del buen maestro. Es abierto y se identifica con los estudiantes son los temas que de manera relevante componen la capacidad de discernimiento que facilita la comprensión del contexto y de quienes lo componen. En cuanto al primero, teniéndose como prioridad el bienestar y felicidad de los estudiantes, se hace referencia a la libertad de escogencia en clase, al respeto de las condiciones personales y a la capacidad de comprensión de las razones de otros. La identificación básicamente se concibe como el estar en contacto con la persona y ser sensible a sus necesidades para dar respuestas apropiadas y diferenciadas.

Las restantes condiciones fueron aportadas por un sólo grupo, y las de mayor frecuencia son propicia autoaceptación y posee visión integral del acto educativo, ambos aspectos aportados por los padres de familia. Parece ser que el interés primordial de este grupo es que el maestro pueda reflejarle positivamente a sus estudiantes sus logros y cualidades, y 
que se interese por su formación integral considerando, a la hora de enseñar, la familia, la salud y la situación socioeconómica de los estudiantes. Es profesional, posee sensibilidad social y profesional autoafirmado son temas del interés de los formadores de educadores, condiciones que consideran básicas para integrarse como miembros del grupo y desde allí impulsar el cambio social y el mejoramiento individual de los estudiantes.

f. Capacidad para la toma de decisiones (escogencia de un curso de acción posterior al análisis de las diferentes opciones)

Este indicador se alimenta de sólo 8 referencias producto del análisis de 6 condiciones del buen maestro. Al hacerse referencia a es responsable de su tarea, es flexible, es abierto, es profesional, y tiene vocación, los formadores de educadores principalmente dieron contenido a este indicador correspondiente a la perspectiva descriptiva de la formación de educadores. El primer aspecto se concreta en el plano de las actitudes puesto que se hizo referencia a que el maestro ideal no delega la responsabilidad de sus actos a otros actores componentes del sistema educativo en general. Los siguientes hacen referencia a algunas herramientas que hacen posible la escogencia de un curso de acción posterior al análisis de las opciones que se tienen, dentro de criterios cualitativos. En cuanto a tiene vocación, se dice que no se trata de que el educador tenga o no vocación sino más bien que construya concientemente una actitud positiva hacia la enseñanza. El aporte específico de los padres de familia se centra en el tema del establecimiento de límites, puesto que desde su punto de vista, el buen maestro sabe definirlos con claridad.

g. Consideración del contexto (condiciones interrelacionadas en las que se da el acto educativo)

Las condiciones interrelacionadas en las que se da el acto educativo es un indicador del enfoque descriptivo que explica 15 referencias, 6 características del buen maestro, con la participación de todos los actores aunque en ninguna de ellas concurrieran los tres grupos. Se encontró consenso entre el grupo de padres y de formadores en los aspectos tiene conocimiento del contexto actual y comprende las relaciones entre hogar y escuela, siendo el primero el que acumuló casi la mitad de las referencias. El buen maestro es el que reconoce la dinámica histórica de la sociedad, la cultura familiar, y actúa en concordancia con éstas. En el tema tiene visión integral del acto educativo coincidieron los estudiantes y los formadores de educadores, dándosele importancia a la multidisciplinariedad y a la perspectiva global a la hora de educar. Las restantes condiciones (conoce a los 
estudiantes, es abierto y es profesional), son producto de la discusión de los formadores de educadores. Conocer el ambiente familiar y la dinámica del aula, facilita la aceptación de las diferencias para un ejercicio profesional pertinente.

h. Individualización de la tarea docente (adaptar de acuerdo con el propósito educativo y la persona)

Este indicador está compuesto por 6 referencias y 3 condiciones del maestro ideal. Conoce a los estudiantes entendido como enseñanza individualizada de acuerdo con la edad, es una condición aportada por los estudiantes y los formadores de educadores. Es abierto está referida a la participación de los estudiantes en la definición de cursos de acción y es producto de la reflexión del grupo de estudiantes. Mediante una preocupación por la socialización de los niños y el estímulo a su creatividad, el grupo de padres de familia enfatiza nuevamente en que el maestro ideal es aquel que tiene una visión integral del acto educativo.

De esta manera se examinan todos y cada uno de los componentes de la idea del buen maestro. Los dos enfoques teóricos para la formación de educadores, el normativo y el descriptivo, fueron los elementos aplicados para explicar las tendencias ideológicas de los participantes con respecto al educador ideal. Esta construcción conjunta, reconstruida o hecha evidente mediante el análisis del campo semántico producto de los grupos de discusión, muestra aquellos elementos que se incluyen con mayor intensidad, y aquellos que si bien son o han sido pertinentes en diferentes momentos históricos, adquieren menor importancia en el sentido social buscado. A partir del anterior análisis, es posible elaborar las conclusiones pertinentes para dar respuesta al problema de esta investigación, es decir, la definición de la correspondencia teórica entre el sentido social de la idea del buen maestro y los enfoques normativo y descriptivo para la formación inicial de educadores.

\section{CONCLUSIONES}

a. La condición tiene personalidad de maestro es el indicador al que mayor importancia se le da en la recopilación hecha sobre el sentido social de la idea del buen educador. La mitad de las condiciones o características enunciadas fueron aportadas por los tres grupos de discusión, y es la categoría con mayor número de referencias. Este es un indicador referido al modelo normativo de formación de educadores, y puede concluirse que prevalece entre los participantes la idea del 
maestro innato. Ante la realidad que es planteada por los cambios sociales a los que se enfrenta el sistema educativo, y en particular el educador, esta perspectiva no contribuye a que este profesional pueda enfrentar la tarea educativa de manera pertinente. La transformación que se ha dado en los estilos de relación entre maestros y estudiantes no puede ser enfrentada considerando como herramienta única, un estilo de personalidad basado en condiciones ideales para la docencia. De acuerdo con el sustento teórico de este trabajo, en la actualidad, en que otros agentes sociales no apoyan decididamente a la educación de niños y jóvenes, en que existe una ruptura del consenso sobre los objetivos de la educación, pero que a la vez se vive un aumento en las exigencias que los grupos sociales hacen al profesional en educación, resulta insuficiente esta perspectiva puesto no que ofrece la versatilidad necesaria para ajustar la tarea con iniciativas personales creativas, que faciliten la construcción de relaciones significativas entre profesores y sus estudiantes.

b. La categoría aplica estrategias de pensamiento, referente al modelo descriptivo de formación de educadores, ocupa el segundo lugar en cuanto a la frecuencia de referencias, y está conformada por igual número de condiciones que la categoría anterior, pero sólo una de ellas fue aportada por los tres grupos de discusión. Contrario a lo explicitado en la conclusión anterior, la imagen del buen educador va más allá de una concepción estática de este profesional, más bien mecanisista, en la que ciertas condiciones de personalidad parecen hacer "el milagro" (presagioproducto), para centrarse más bien en una expectativa asociada con la formación profesional, con las exigencias del estudio sistemático, con el aporte de diferentes corrientes pedagógicas, y con la colaboración decidida de una estructura académica en las instituciones de formación docente. Al valorarse la capacidad de razonamiento del maestro como aspecto predictor de su efectividad docente, y aunque esta valoración no alcance el mismo nivel de confluencia entre participantes del estudio, se enfatiza en la necesidad de ofrecer una formación inicial sólida y sistemática, para el desarrollo de destrezas cognitivas relacionadas con la percepción, la capacidad de valorar aportes teóricos, el desarrollo de destrezas de análisis para la toma de decisiones, en fin, todo lo relacionado con la capacidad de razonamiento. La situación encontrada en los resultados de este estudio, tal vez un tanto contradictoria, parece encontrar explicación en valoraciones de diferente naturaleza, sobre la figura del educador, figura polémica a la que en la actualidad se le demanda el cumplimiento de 
una tarea que transita entre el arte y la ciencia de enseñar, y entre lo predecible e inmutable y el dinamismo de la conducta y el pensamiento humano.

c. En cuanto a frecuencia de referencias, el tercer lugar lo ocupa el indicador conductas del enfoque normativo, pero sin que se encontrara concurrencia de los tres grupos de discusión de ninguna de las condiciones enumeradas. Ya se había indicado en los referentes teóricos del trabajo, que a lo largo del tiempo se ha constatado el predominio de tendencias para la formación de educadores, y para la evaluación de su desempeño, basadas en normas que idealmente deben adoptarse como componentes de la personalidad o de la conducta del profesor. Estos supuestos aplicados a la formación pueden ser producto de concepciones ideológicas referentes al buen desempeño docente, pero a la vez este sentido social puede haber incidido en la escogencia de enfoques para la formación y evaluación docente. Lo cierto es que el paradigma proceso-producto, que pone énfasis en la aplicación de conductas específicas definidas como condicionantes del rendimiento de los estudiantes, explica con bastante pertinencia, parte del sentido social de la idea de un buen maestro, que lo describe como un profesional al que se le ha enseñado o debería enseñársele, lo que debe hacer, lo que debe pensar y lo que debe evitar para realizar su tarea educativa, concepción bastante rígida que difícilmente le facilita herramientas para resolver situaciones relacionadas con la escasez de recursos didácticos, con la atención de problemáticas sociales de los estudiantes, o con la atención de condiciones culturales surgidas de manera abrupta y particular en la constelación de microculturas que conforman la sociedad actual y cada grupo de estudiantes, por ejemplo.

d. En cuarto lugar en el número de referencias se encuentra el indicador o categoría aplica estrategias de percepción u observación del enfoque descriptivo, con sólo una condición aportada por los tres grupos de participantes. De acuerdo con la teoría que sustenta este trabajo, este enfoque resulta ser de mayor pertinencia a la formación y evaluación docente; no obstante, se presenta con menor intensidad en la presente caracterización del sentido social de la idea de un buen maestro. La observación o percepción sistemática de la realidad en el aula permite al educador procesar y comunicar información a sus estudiantes, a la vez que desarrolla competencias más bien genéricas que particulares para responder a sus intereses y necesidades. Ciertamente, al ser este un estudio cualitativo en el que tanto lo incluido como lo excluido, o como en este caso, lo escasamente sentido por los participante, 
son parte de una idea común, realmente es preocupante el hecho de que a condiciones como la expuesta, se le de menor relevancia con respecto a otras que no aportan positivamente a la concepción del buen maestro. Existe una idea arraigada que dificulta las valoraciones sociales de este profesional puesto que las expectativas no necesariamente responden a lo pertinente en este campo.

e. Considera el contexto, demuestra capacidad para la toma de decisiones e individualiza la tarea son las categorías que menor número de referencias tienen y sin concurrencia de condiciones en los tres grupos de discusión por lo que se concluye que son los aspectos a los que menor importancia se le dan. Todas ellas son representantes del enfoque descriptivo de formación de educadores, y representan elementos que, desde el punto de vista teórico, favorecerían una mejor comprensión de la tarea docente, y una demanda más congruente de funciones específicas a estos profesionales. En el marco de referencia teórica se había dado cuenta del surgimiento del paradigma contextual o ecológico como elemento no sólo enriquecedor de la tarea docente, sino como aspecto sustantivo para la interpretación del acontecimiento educativo. La consideración de este componente a la hora de conformar la idea de un buen maestro, tanto por parte de lo miembros de la comunidad, como por los mismos educadores, permitiría a estos profesionales dar aportes más contundentes en la resolución del problema de la deserción escolar, en la propuesta de acciones educativas que faciliten una mejor vivencia de la sexualidad, y en el aprovechamiento de los recursos ambientales para la atención de estudiantes con discapacidad, entre otras cosas. El conocimiento, comprensión e interpretación del contexto son elementos que se constituyen en la antesala de una toma de decisiones pertinentes por parte de los educadores, y posibilita una mejor individualización de la tarea. Resulta entonces preocupante la menor atención que se le pone a este elemento, pero es importantes rescatar que al menos está presente, lo que facilitaría el fortalecimiento de esta perspectiva mediante acciones deliberadas por parte de quienes proponen y dirigen las políticas educativas del país.

f. De acuerdo con la propuesta teórica del trabajo, los indicadores del enfoque normativo son tres, a saber, tiene personalidad de maestro, tiene destrezas de maestro, practica conductas de maestro. En total, referidas a este enfoque, fueron adscritas 16 diferentes condiciones del sentido social de la idea de un buen maestro. Las que se repiten en los tres indicadores son es profesional y establece límites, además de que son las condiciones con mayor número de referencias, por lo que se 
puede concluir que son a las que mayor importancia se les dio en el presente estudio desde una perspectiva normativa. Obsérvese que estos dos elementos reflejan la importancia que se le da al acto educativo como proceso de dos vías; por parte del educador la disposición de realizarlo dentro de los parámetros definidos y certificados para el ejercicio de la enseñanza como ciencia, arte y oficio; de parte del estudiante la predisposición hacia el aprendizaje mediante un comportamiento adecuado a las exigencias de la situación, no obstante que se le exige al educador que sea el responsable de mantener esta predisposición mediante el establecimiento de normas de disciplina en el aula. El predominio del punto de vista normativo en la idea del buen maestro es un asunto que debe ser atendido cuidadosamente tanto en los planes de formación inicial de educadores, como en los procesos de evaluación de la docencia, en vista de que refleja una expectativa social que poco contribuye al desarrollo de un sentimiento de adecuación a la tarea docente por parte del profesorado.

g. De acuerdo con la propuesta teórica del trabajo, los indicadores del enfoque descriptivo son cinco, a saber, desarrolla y aplica estrategias de pensamiento, desarrolla y aplica estrategias de percepción u observación, desarrolla su capacidad para la toma de decisiones, sabe considerar el contexto y puede individualizar la tarea. A estos indicadores se adscriben 18 diferentes condiciones del buen maestro, y las que se repiten en cuatro de los indicadores son es profesional, conoce a sus estudiantes y es abierto. La primera condición es la que mayor número de referencias tiene, lo que es coincidente con la imagen de buen maestro que se tiene desde la perspectiva normativa. Sin embargo la diferencia que confirma la visión descriptiva de la función profesional del docente, es decir, su capacidad para describir la tarea y encontrar las mejores alternativas de actuación docente, está en que el ser profesional es acompañado por condiciones producto de su capacidad de razonamiento alrededor de situaciones concretas de los estudiantes y el ambiente en que se desarrolla el acto educativo. Es decir, si bien es pertinente destacar la condición de profesional como parte importante del sentido social de la idea del buen maestro. Esta condición se ubica en su correcta dimensión (descriptiva) al ser acompañada por otras que exigen del educador una formación crítica y analítica que le permita la consecución de competencias genéricas para decidir sobre el comportamiento más adecuado a la realidad de los estudiantes. 
h. La condición del buen maestro a la que mayor importancia se le dio en el presente estudio es el profesionalismo, entendido desde ambas perspectivas, la normativa y la descriptiva. Independientemente del predominio de visión desde el cual se valora la condición profesional del educador, es importante reconocer la aceptación social hacia un tipo de formación que le permita al educador partir de los problemas educativos de la práctica cotidiana en el mundo actual, utilizando la teoría como instrumento para analizar y reflexionar sobre esa práctica. Esta condición preponderante representa un compromiso muy grande para las universidades costarricenses, y para los administradores del sistema educativo puesto que sus políticas y mecanismos de gestión, deben respetar y responder a las exigencias del ejercicio profesional en el campo de la educación. Este hecho consolida y da mayor autenticidad a los esfuerzos hechos por la profesionalización docente vista como parte de un proceso de desarrollo que deberá ser estimulado en todo momento y desde diferentes instancias como las universidades y el Ministerio de Educación.

Con base en las anteriores conclusiones puede indicarse que existen grandes expectativas acerca de la labor docente por parte de quienes participaron en la construcción del sentido social de un buen maestro. Independientemente de la prevalencia de un enfoque u otro para explicar o sustentar dichas expectativas, resulta muy claro que a este grupo de profesionales se les demanda una actuación comprometida y sustentada teóricamente. El reto de las instituciones formadoras de educadores es muy grande, así como el reto individual que asume cada persona al elegir la profesión docente. Esta deberá ser la reflexión exigida sobre todo durante su período de formación inicial.

\section{RECOMENDACIONES}

\section{- En el campo de la investigación}

a. Utilizar los resultados de este estudio para la elaboración de instrumentos diagnósticos que permitan la caracterización generalizada del sentido social de la idea de un buen maestro en el país, por región y por estratos socioculturales, entre otras poblaciones.

b. Ampliar el presente estudio con la perspectiva de los propios profesores, de manera que se pueda contrastar la información e identificar el nivel de autoafirmación profesional del profesorado de acuerdo con sus grupos de afiliación. 
c. Utilizar los resultados del presente estudio para la evaluación de los enfoques teóricos de los planes de formación de educadores en las universidades costarricenses.

d. Identificar el nivel de confluencia de intereses entre las políticas educativas del país, y el sentido social de la idea del buen maestro.

e. Identificar elementos para enriquecer los planes de formación de educadores en las universidades costarricenses.

f. Elaborar manuales o instrumentos de autoayuda, basados en los resultados del presente estudio, para favorecer el desarrollo profesional del profesorado.

- Al Ministerio de Educación Pública

a. Poner a disposición de las instancias que brindan formación continua a los educadores nacionales, los resultados de este estudio, con el propósito de que se extraigan criterios que enriquezcan la propuesta y evaluación de los cursos de formación continua de estos profesionales.

b. Recomendar al Ministerio de Educación y a las organizaciones magisteriales, utilizar los resultados de este estudio para el análisis de los criterios utilizados por el Ministerio de Educación en sus propuestas de proyectos para el mejoramiento de la imagen del educador costarricense.

c. Incluir dentro de los cursos de formación continua del profesorado, talleres de reflexión en cuanto a la imagen profesional propia, y la reconstrucción de esta imagen orientada por perspectivas de carácter descriptivo.

d. Realizar un análisis de los instrumentos de evaluación anual del profesorado, con el objeto de excluir indicadores de tipo normativo, e incluir indicadores basados en la adquisición de competencias genéricas para la ejecución del papel docente.

\section{Referencias}

Arroyo, J. A. (2001). Incidencia de los indicadores en la calidad de la educación. San José: Editorial de la Universidad de Costa Rica.

Blázquez Entonado, F. (1997). Formación y desarrollo del profesorado de educación secundaria. En Formación psicopedagógica del profesorado de secundaria. $F$. Blázquez Entonado; T. González Bravo; M. Montanero Fernández. Badajoz: ICE, Universidad de Extremadura. 
Canales, M.; Peinado, A. (1994). Grupos de discusión. En Métodos y técnicas cualitativas de investigación en Ciencias Sociales. Juan Manuel Delgado y Juan Gutiérrez, coordinadores. Madrid: Editorial Síntesis S.A.

Costa Rica, Ministerio de Educación Pública. (2000). Reglamento para el reconocimiento del incentivo por certificación voluntaria. San José: Ministerio de Educación.

De Landsheere, G. (1999). El pilotaje de los sistemas educativos. $2^{\circ}$ ed. Madrid: Editorial La Muralla, Cooperación Iberoamericana.

Esteve, J. M. (1996). La formación inicial del profesorado de educación secundaria. Rev. Signos. Teoría y práctica de la educación, (18), 42-54.

Esteve, J.M.; Franco, S.; Vera, J. (1995). Los profesores ante el cambio social. Barcelona: Editorial Anthropos.

García Carrasco, J.; García del Dujo, A. (1996). Teoría de la educación. I y II. _Salamanca, España: Ediciones Universidad de Salamanca.

Gutiérrez, J.; Delgado, J.M. (1994). Teoría de la observación. En Juan Manuel Delgado y Juan Gutiérrez, coordinadores, Métodos y técnicas cualitativas de investigación en Ciencias Sociales. Madrid: Editorial Síntesis.

Imbernón, F. (1994). La formación del profesorado. Barcelona: Paidós.

Kasambira, P. (2000). Counseling and Human Ecology: A Conceptual Framework for Counselor Educators. Eighth International Conference. Counseling in the 21 st. Century. San José, Costa Rica.

Madriz, E. (2000). Focus Groups in Feminist Research. Handbook of Qualitative Research. 2dn. Ed. (Denzin, N.; Lincoln, Y. editors) London: Sage Publications.

Marcelo, C. (1994). Formación del profesorado para el cambio educativo. Barcelona: PPU. 
Marchesi, A.; Martín, E. (1998). Calidad de la enseñanza en tiempos de cambio. Madrid: Alianza Editorial.

McMillan, J. (1996). Educational Research. Fundamentals for the Consumer. USA: Harper Collins College Publishers.

Navarro, P.; Díaz, C. (1994). Análisis de contenido. En Juan Manuel Delgado y Juan Gutiérrez, coordinadores, Métodos y técnicas cualitativas de investigación en Ciencias Sociales. Madrid: Editorial Síntesis.

Noya, F. (1994). Metodología, contexto y reflexibilidad. Una perspectiva constructivista y contextualista sobre la relación cualitativo - cuantitativo en la investigación social. En Juan Manuel Delgado y Juan Gutiérrez, coordinadores, Métodos y técnicas cualitativas de investigación en Ciencias Sociales. Madrid: Editorial Síntesis.

Proyecto Estado de la Nación en desarrollo humano sostenible. (2002). Octavo informe Estado de la Nación en desarrollo humano sostenible. San José, Costa Rica: Proyecto Estado de la Nación.

Rueda Beltrán, M.; Díaz Barriga, F. (2000). Evaluación de la docencia, perspectivas actuales. México: Piados.

Taylor, S.J.; Bogdan, R. (1996). Introducción a los métodos cualitativos de investigación. Barcelona: Piados.

Van Dalen, D.; Meyer, W. (1971). Manual de técnica de la investigación educacional. Buenos Aires: Editorial Paidos. 